\title{
A Survey of Geologic Resources
}

\author{
J. Edmunson and D. L. Rickman
}

\section{Introduction}

This chapter focuses on the resources available from the Moon itself: regolith, geologically concentrated materials, and lunar physical features that will enable habitation and generation of power on the surface. This chapter briefly covers the formation of the Moon and thus the formation of the crust of the Moon, as well as the evolution of the regolith. The characteristics of the regolith are provided in some detail, including its mineralogy and lithology. The location of high concentrations of specific minerals or rocks is noted. Other ideal locations for in situ resource utilization technology and lunar habitation are presented.

This chapter is intended to be a brief review of current knowledge, and to serve as a foundational source for further study. Each concept presented here has a wealth of literature associated with it; the reader is therefore directed to that literature with each discussion. With great interest in possible manned lunar landings and continued study of the Moon by multiple satellites, the available information changes regularly.

\section{Formation and Evolution of the Moon}

Given the similarities in composition, the nearly-identical oxygen isotopic signature of the Earth and Moon, and the angular momentum of the Earth-Moon system, the Moon likely formed when an oblique, "Giant Impact" occurred between the proto-Earth and a Mars-sized impactor (e.g.; Hartmann and Davis, 1975). Debris from this impact, made of material from both the impactor and the proto-Earth, was lofted into orbit around the Earth (e.g.; Canup and Asphaug, 2001) and may have undergone diffusive equilibration (e.g.; Pahlevan and Stevenson, 2007). Accretion of this debris, by gravity, contained sufficient energy to melt the Moon and form it into a sphere. At this stage, the Moon had a magma ocean.

There are two widely recognized models for the formation of the lunar crust. The first involves crystallization of minerals during the slow cooling of the magma ocean. This model, termed the "lunar magma ocean" model, claims that dense minerals, such as olivine and pyroxene, sank to the bottom of the lunar magma ocean as they formed, while the mineral anorthite (Ca-rich plagioclase), which was less dense than the residual relatively Fe-rich surrounding magma, floated to the top and formed the lunar highlands crust (e.g.; Smith et al., 1970; Wood et al., 1970). In the second model, the "postmagma ocean" model, the magma ocean cooled, but did not form an anorthositic (anorthite-rich) crust (Longhi, 2003). Early convection and density adjustments caused heating and partial melting of the upper layer of the Moon; the liquid produced during partial melting separated into a less dense anorthositic parent liquid and a denser pyroxenite (pyroxene-rich) liquid. The less dense anorthositic liquid then reached the 
surface and formed the anorthosites. Although there remains some debate as to which model is more likely, both explain the presence of an anorthositic crust on the Moon.

Both formation models agree upon the need for a density overturn in the Moon after crust formation. The density of cumulates (a term used to describe accumulated minerals) increases with decreasing depth because iron-rich minerals form after less dense magnesium-rich minerals. Thus, the denser minerals form after the less dense cumulates have already crystallized and settled to the bottom. For cumulate pile gravitational stability, the densest cumulates must be at the bottom. As a consequence, cumulates overturned in the mantle. Recent articles pertaining to the lunar magma ocean and crustal formation on the Moon call upon this process to explain the array of geochemical sources observed for lunar samples (e.g.; Parmentier et al, 2002; ElkinsTanton et al., 2011).

\section{Impacting the Lunar Surface}

After crystallization of the anorthositic crust, the Moon was subjected to intense bombardment by meteorites; the lunar surface was shaped by over four billion years of impacts. The resulting broken rock that separates the Moon's bedrock from space, the lunar regolith, evolved from repeated impacts, including those from micrometeorites. The repeated impact "tilling" of the regolith gave rise to the term "gardening", which describes the impact-driven process by which fresh surface material is exposed and other surface material is buried on the Moon. This process also gave rise to the lunar "soil"; collections of regolith particles less than $1 \mathrm{~cm}$ in size are referred to as soils (McKay et al., 1991). Figure 1 shows some attributes of the regolith.

One of the largest crater basins in the Solar System is on the Moon; it is called the South Pole-Aitken Basin. This crater basin is also one of the oldest in the Solar System. According to Wilhelms (1987), the average crater size decreased as the age of the Moon increased, indicating a decrease in the size of the impactors and the flux of impactors over time. That is not to say small impacts were not part of the early bombardment of the Moon, but that they were covered by larger (or later) crater ejecta. The impactor size was likely a complete continuum, from the largest to the smallest size possible; in addition to the large impact craters observable from Earth, the Moon has extremely small, even microscopic, craters - these are from micrometeorites (typically $1 \mathrm{~mm}$ or less in size). Figure 2 is a cross-section of a micrometeorite impact crater on the surface of Apollo 16 sample 62236.

The Moon experiences hypervelocity impacts (e.g.; Hörz et al., 1991; French 1998). That is, an impactor will hit the lunar surface traveling at speeds greater than $3 \mathrm{~km} / \mathrm{s}$ (Hörz et al., 1991). At impact, the lunar surface is compressed at the impact site. A shock wave travels outward from the impact site, pushing all surrounding rocks outward and, depending on the energy, vaporizing the impacting body. A portion of the Moon will also be vaporized and more of it will be melted. If the melt is small enough it will chill rapidly and make impact melt glass. The shock wave throws out near-surface material (ejecta) which blankets the surrounding area. In most cases, the uppermost 
impacted rocks are melted. Rocks surrounding the impact site that are not melted will rebound as a result of the rarefaction wave, but will be brecciated (broken) in the process as they do not have sufficient elastic properties. Craters are filled with vertically ejected material and portions of the crater walls that exceeded the angle of repose. This includes any original ejecta on the original crater rim. The final crater, known as the apparent crater, appears shallower than the original crater. Impacts with more energy will cause uplift in the center of some craters; the central peak forms as a result of concentrated upward motion of a rarefaction wave (e.g.; Dence, 1968). These highenergy, central uplifted craters are called complex craters, whereas those without central peaks are called simple craters.

Micrometeorite impacts create tiny simple craters, and are also responsible for the formation of lunar agglutinates. Agglutinates are aggregates of other regolith particles on the lunar surface, including other agglutinates. These aggregates are held together by vesicular (hole-bearing) impact melt glass. Agglutinates are typically less than $1 \mathrm{~mm}$ in size and can constitute approximately $60 \%$ of studied mature lunar soils by volume (Papike et al., 1998). In addition, the abundance of agglutinates increases with decreasing grain size and increasing maturity of the regolith (e.g.; McKay et al., 1974; Taylor et al., 2001). Maturity, in the lunar sense, describes how long the surface layer has been exposed to space; this refers to space weathering. Micrometeorites can also create vapor coatings on lunar materials. These coatings do not have the same chemical characteristics as the host sample, therefore they must have been deposited and not created in situ (e.g.; Keller and McKay, 1993 and 1997; Hapke, 2001; Taylor et al., 2010). This type of space weathering is also apparent on the surface of Mercury (e.g.; Cintala, 1992; Hapke, 2001).

\section{Space Weathering}

Impacts are included in a group of processes referred to as "space weathering". In addition to impacts, space weathering describes the effects of cosmic ray, solar wind, and ultraviolet (UV) radiation exposure. These particular processes influence the exposed surface, but the effects can be observed in samples placed at depth due to gardening.

Galactic cosmic ray particles have energies of $100 \mathrm{MeV}$ to $10 \mathrm{GeV}$, and can change the isotopic and elemental chemistry of the surface with which they interact. Neutron capture reactions can create higher concentrations of specific isotopes (e.g., ${ }^{150} \mathrm{Sm}$ from ${ }^{149} \mathrm{Sm}$ ) on a planet's surface; this effect decreases with depth (e.g.; Lingenfelter et al., 1972). Scientists have used this technique to determine the age of exposure and the depth at which the sample was exposed to cosmic rays. The cosmic ray particles can also produce lighter elements and isotopes, such as ${ }^{15} \mathrm{~N}$ used by Mathew and Marti (2001) to calculate the rate of spallation (the expulsion of atoms or atomic nucleus components) at the lunar surface.

The Moon's lack of an atmosphere allows very concise study of solar wind particles and their implantation. Solar wind describes the abundant, low-energy ( $1 \mathrm{KeV})$ particles (i.e., 
protons, electrons, and alpha particles to a lesser extent, as well as light volatile elements) being emitted by the Sun and implanted, typically to a depth of a few tens of nanometers, into the lunar surface (e.g.; Lucey et al., 2006 and references therein). Solar energetic particles, those accelerated to $1-100 \mathrm{MeV}$, can be implanted up to approximately $1 \mathrm{~cm}$ in depth. Much of the solar-implanted material remains implanted, but some is able to diffuse out of the rock. Thus, solar-implanted material is not used to determine the age of exposure of the lunar surface.

Ultraviolet radiation exposure and its effect on minerals is a relatively new field of study. Wong et al. (2010) noted degradation of forsterite during exposure to UV radiation and observed a shift in the peak center and shape of Raman spectra. Wong et al. (2010) claim that UV radiation causes the crystal lattice order to become disordered, and may in fact liberate $\mathrm{O}_{2}$ gas. Future work is planned to further quantify the effects of UV radiation on minerals.

Lunar geologists use maturity as an index used to describe how long a regolith surface resided at or near the surface of the Moon. Mature lunar regolith has evidence of space weathering; changes in isotopic and elemental composition, micrometeorite impacts, a darkening of the albedo, and the formation of nanophase iron. The maturity of the lunar regolith can indicate its grain size, from the counteracting properties of comminution (breaking apart, destruction) by impact and agglutination (welding together of particles with impact melt glass); this process was studied in detail by McKay et al. (1974) and Lindsay (1975). The magnetic properties of lunar materials are also influenced by space weathering. Superparamagnetic nanophase iron is formed by space weathering; it carries a characteristic electron spin resonance of $g=2.1$ (Hapke et al., 1975). This material also lowers the albedo of lunar regolith, in particular the fine fraction $(<25 \mu \mathrm{m})$ when compared to powdered lunar rocks of analogous composition (Hapke et al., 1975; Pieters et al., 1993). Space weathering induces a higher absorption coefficient (the change in albedo), an absence of absorption bands, and a decrease in the absorption with increasing wavelength (Hapke et al., 1975). A way to quantify the maturity of lunar soils by using their optical (spectral) characteristics, abbreviated OMAT, was presented by Lucey et al (2000). This particular measure of maturity compares the reflectance ratio of 950 and 750nm to a hypothetical dark red "hypermature" end-member composition. Another way to express maturity is the use of $I_{s} / F e O$ (Morris, 1978). In this measure, the intensity $\left(I_{s}\right)$ of the ferromagnetic resonance of the sample at $g=2.1$ is divided by the concentration of $\mathrm{FeO}$ in the sample. Immature samples have a ratio of 0 to 29 , submature from $30-59$, and mature is greater than or equal to 60 . Note that maturity does not depend on the type of rock at the lunar surface.

\section{Characteristics of the Lunar Regolith}

\section{Physical Description}

The lunar regolith is composed of mineral fragments, impact melt glasses and glass beads, agglutinates, and localized occurrences of volcanic glass beads. The depth of the regolith is estimated to be between 4 and $5 \mathrm{~m}$ in mare areas, and 10 to $12 \mathrm{~m}$ in 
highland areas (McKay et al., 1991); and has been determined, using radar and optical data, to average between 5 and 12m globally (e.g.; Shkuratov and Bondarenko, 2001). In contrast to all terrestrial geologic materials, the lunar regolith is not effectively sorted in either size or shape. The size of lunar regolith particles varies from sub-micron to stadium-sized boulders on the surface. However, most of the regolith (up to $90 \%$ in some measurements) is below $1 \mathrm{~cm}$ (Heiken et al., 1974). Carrier (2003) compiled measurements from the sub-centimeter fraction and determined a particle size distribution (Figure 3). In general, the shape of lunar regolith particles is very angular because there is no observed widespread weathering process on the Moon equivalent to that on the Earth (i.e., wind and water-involved chemical and mechanical breakdown processes). Some particles, including impact-generated and volcanic glass beads and some agglutinates, have rather spherical or smooth shapes. Quantitative lunar particle shape data is lacking, although a few have attempted to characterize them (e.g.; Carrier et al., 1991; Liu et al., 2008; and references therein). Due to the majority of the particles being elongated, and the mechanisms such as moonquakes that pack the particles, preferred orientation of particles has been noted in Apollo core samples (e.g.; Carrier et al., 1991). The packing of these particles gives rise to the density of the regolith. The average bulk density of the regolith was determined to be $1.5 \mathrm{~g} / \mathrm{cm}^{3}$ and includes void spaces; the specific gravity of the lunar regolith averages $3.1 \mathrm{~g} / \mathrm{cm}^{3}$ and does not include void spaces (Carrier et al., 1991, and references therein). Carrier et al. (1991) determined that, if in situ lunar regolith was excavated, the top $3 \mathrm{~m}$ would remain vertical, and a $60^{\circ}$ slope would survive to a depth of approximately $10 \mathrm{~m}$. If lunar regolith was excavated and compacted, a $45^{\circ}$ slope would survive. If the regolith was simply dumped on the surface, the angle of repose would be near $40^{\circ}$.

\section{Particle Textures}

There are numerous textures observed in lunar regolith particles. The following list explains some general geologic terms for textures in regolith particles. These terms are explained here to provide a way for simulant users and regolith examiners to understand some of the geologic literature on the Apollo and simulant samples.

- Holocrystalline: entirely crystalline (this does not necessarily mean the particle is a single crystal, although that may be the case). An example would be a brecciated mineral or rock clast (piece).

- Holohyaline: entirely glass. Examples include impact melt glass, agglutinate glass, and most volcanic glass beads.

- Hypocrystalline: contains both crystals and glass. Examples include agglutinates and some impact melts, as well as rocks created from the shock lithification (making into a rock) of regolith (these are called regolith breccias).

Some of the textures observed in lunar regolith particles have more specific textures. Figure 4 illustrates some common textures observed in Apollo 16 regolith core samples.

- Poikiloblastic: a metamorphic texture in which a single crystal of one mineral encloses many smaller grains of other minerals.

- Granulitic: a completely recrystallized rock that retains none of its original texture. 
- Intersertal: unaligned plagioclase crystals that are relatively large in size making up a substantial portion of a rock.

- Spherulitic: fibrous crystals that radiate from a point and are clustered in spherical groups. Can be a sign of devitrification (the formation of crystals in hot glass)

- Subophitic: pyroxene and plagioclase grains of similar size, with pyroxene encompassing the ends of some plagioclase grains.

\section{Chemical Composition}

A review of the chemistry, mineralogy, and petrology of lunar soil samples $<1 \mathrm{~mm}$ in size was published by Papike et al. (1982). The following table is data from this reference, collected initially by instrumental neutron activation analysis. Note there are several conventions in such a table that are standard practice in geology. The elements reported are referred to as the major, rock forming elements. Other elements are certainly present and could even be nearly as abundant as some of the elements reported here. The compositions are presented as oxide weight percent, not element weight percent; this does not imply that these specific oxides exist on the Moon and are not intended to represent oxide minerals or species. For the actual chemistry see the following section on mineralogy. The total will not sum to $100 \%$ for several reasons, such as unmeasured components, non-stoichiometry, and time sensitivity of the technique; the totals can be imprecise individually or collectively by several percent. Iron is shown as $\mathrm{Fe}^{2+} \mathrm{O}$, although it may actually be in more than one valence state (e.g., $\mathrm{Fe}^{0}$ and $\mathrm{Fe}^{3+}{ }_{2} \mathrm{O}_{3}$ ) on the Moon.

Table 1: Compositions of Apollo soils $(<1 \mathrm{~mm})$ in oxide weight percent (Papike et al., 1982).

\begin{tabular}{|l|c|c|c|c|c|c|}
\hline & 10084,1591 & 12003,464 & 14163,778 & 15271,27 & 64501,122 & 72501,15 \\
\hline $\mathrm{SiO}_{2}$ & 41.3 & 46.9 & 47.3 & 46.0 & 45.3 & 45.2 \\
\hline $\mathrm{TiO}_{2}$ & 7.5 & 2.3 & 1.6 & 1.5 & 0.37 & 1.4 \\
\hline $\mathrm{Al}_{2} \mathrm{O}_{3}$ & 13.7 & 14.2 & 17.8 & 16.4 & 27.7 & 20.1 \\
\hline $\mathrm{Cr}_{2} \mathrm{O}_{3}$ & 0.290 & 0.387 & 0.200 & 0.350 & 0.090 & 0.230 \\
\hline $\mathrm{FeO}$ & 15.8 & 15.4 & 10.5 & 12.8 & 4.2 & 9.50 \\
\hline $\mathrm{MnO}$ & 0.213 & 0.195 & 0.135 & 0.162 & 0.056 & 0.120 \\
\hline $\mathrm{MgO}$ & 8.0 & 9.2 & 9.6 & 10.8 & 4.9 & 10.0 \\
\hline $\mathrm{CaO}$ & 12.5 & 11.1 & 11.4 & 11.7 & 17.2 & 12.5 \\
\hline $\mathrm{Na}_{2} \mathrm{O}$ & 0.41 & 0.67 & 0.70 & 0.49 & 0.44 & 0.44 \\
\hline $\mathrm{K}_{2} \mathrm{O}$ & 0.14 & 0.41 & 0.55 & 0.22 & 0.10 & 0.17 \\
\hline $\mathrm{Total}$ & 99.8 & 100.8 & 99.8 & 100.4 & 100.3 & 99.7 \\
\hline
\end{tabular}

Note: Apollo sample number (5 digits) is followed by split number.

\section{Mineralogy and Constituent Phases}

The vast majority of the Moon's surface is composed of a few silicate minerals (plagioclase feldspar, pyroxene, and olivine). In these minerals, the silicon is in tetrahedral coordination with four oxygen atoms. The mineralogy of lunar regolith 
dictates most of its properties, such as melting temperature, abrasivity, strength, and trace element distribution. For example, the olivine mineral group melts between $1200^{\circ} \mathrm{C}$ (pure $\mathrm{Fe}$ olivine, fayalite) and $1890^{\circ} \mathrm{C}$ (pure $\mathrm{Mg}$ olivine, forsterite) at one atmosphere pressure, depending on its composition (Figure 5). Because olivine's composition can range between $100 \% \mathrm{Fe}_{2} \mathrm{SiO}_{4}$ and $100 \% \mathrm{Mg}_{2} \mathrm{SiO}_{4}$ (both $\mathrm{Fe}$ and $\mathrm{Mg}$ are +2 cations with similar ionic radii), this range is called a "solid solution". Estimates for the hardness of fayalite on the Mohs hardness scale are approximately 6.5 (approximately 700 on the Knoop hardness scale), whereas the hardness of forsterite is estimated to be 7 (approximately 850 on the Knoop hardness scale). Olivine has an affinity for other +2 cations (such as platinum-group elements, $\mathrm{Cr}^{2+}, \mathrm{Mn}, \mathrm{Ca}$, and $\mathrm{Sr}$ ), as well as small +3 cations (such as $\mathrm{V}^{3+}$ and the heavy rare earth elements). Vanadium ${ }^{2+}$ also substitutes into the structure because the lunar environment is exceedingly reducing (e.g.; Papike et al., 2005).

Plagioclase is another mineral group, and is the most abundant crystalline, and shocked diaplectic glass, component of the lunar crust. In fact, the lunar highlands are dominated by plagioclase, and a significant amount of plagioclase can also be found in lunar mare. Plagioclase is the name given to the solid solution between anorthite $\left(\mathrm{CaAl}_{2} \mathrm{Si}_{2} \mathrm{O}_{8}\right)$ and albite $\left(\mathrm{NaAlSi}_{3} \mathrm{O}_{8}\right)$. This solid solution employs "coupled substitution". That is, $\mathrm{Ca}^{2+}+\mathrm{Al}^{3+}$ are substituted by $\mathrm{Na}^{1+}+\mathrm{Si}^{4+}$ in the plagioclase structure. The composition of the mineral is often denoted by molar percent of calcium; thus, $A n_{100}$ has $100 \% \mathrm{Ca}$ (anorthite) and $\mathrm{An}_{0}$ has $0 \% \mathrm{Ca}$ (albite). Figure 6 presents the temperature regimes for the plagioclase series. Note that plagioclase encompasses the minerals albite $\left(A n_{0-10}\right)$, oligoclase $\left(A n_{10-30}\right)$, andesine $\left(A n_{30-50}\right)$, labradorite $\left(A n_{50-70}\right)$, bytownite $\left(A n_{70-90}\right)$, and anorthite (An $\left.n_{90-100}\right)$. Most of the lunar highland plagioclase is approximately $A n_{95}$ (Heiken et al., 1991) due to a lack of sodium on the Moon, whereas bytownite and anorthite are both found in mare basalts (e.g.; Karner et al., 2004). Minor and trace elements found in plagioclase minerals include $\mathrm{Sr}$, which substitutes readily for $\mathrm{Ca}$, and light rare earth elements. The element $\mathrm{Eu}$, which can have both $2+$ and $3+$ ionic charges, tends to substitute in significant abundance into the $\mathrm{Ca}^{2+}$ site of the plagioclase structure as $\mathrm{Eu}^{2+}$. This particular substitution leads to a "positive Eu anomaly" in plagioclase rare earth element patterns. The hardness of well-crystallized plagioclase is 6 on the Mohs scale (approximately 550 on the Knoop scale). The hardness of lunar plagioclase may frequently be less (Cole, et al., 2010) presumably due to shock-induced features such as fractures or diaplectic glass formation.

Pyroxene is the final mineral group that is a major component of the lunar crust. Pyroxene has four end-member compositions: enstatite $\left(\mathrm{MgSiO}_{3}\right)$, ferrosilite $\left(\mathrm{FeSiO}_{3}\right)$, diopside $\left(\mathrm{CaMgSi}_{2} \mathrm{O}_{6}\right)$, and hedenbergite $\left(\mathrm{CaFeSi}_{2} \mathrm{O}_{6}\right)$. Pyroxene can be almost any composition between the four end-members, although cooling conditions and temperature/pressure changes can result in exsolution (the formation of two minerals from a crystal of a single composition, Figure 4b). Figure 7 shows the pyroxene quadrilateral, with the four end-member compositions, and compositions of lunar pyroxenes. The variations in the composition (and crystallographic structure) of pyroxene by major and minor elements cause variations in the hardness, from 5-6.5 on the Mohs hardness scale (approximately 320 to 850 on the Knoop scale). Minor and 
trace elements normally found in pyroxenes are $\mathrm{Mn}, \mathrm{Sr}, \mathrm{Cr}^{3+}$, and heavy rare earth elements.

Glass is a ubiquitous component of regolith and can be the dominant phase. There are two different sources of glass in the regolith. By far, the most dominant source of glass is impact. The melt produced during impact typically solidifies quickly, creating impact melt glass. Large amounts of impact melt, often produced in large-scale impacts, can cool slowly enough to crystallize. Not only is impact melt produced during large-scale impacts (such as the impact melt sea in the crater Copernicus), impact melt is produced in small-scale micrometeorite impacts as well. This glass produces lunar agglutinates. The vesicular nature of agglutinates makes them incredibly fragile. Impact-produced glass is found globally on the Moon. In contrast, volcanic fire-fountaining, the release of molten material balistically, is a highly localized source of glass in the regolith. The molten material ejected from lunar volcanic vents solidifies quickly in the cold, lowgravity environment. In special cases this resulted in spherical or near spherical glass beads, and the color of the glass beads reflects the composition of the beads. Specific deposits of colored glass beads were observed in significant quantities by the Apollo 15 (green glass) and Apollo 17 (orange and black glass) crews. The difference between these glasses is their composition; green glasses are rich in $\mathrm{Mg}$ and $\mathrm{Fe}$ and poor in $\mathrm{Ti}$, while orange and black glasses are rich in Ti. Orange and black glasses can be distinguished by their crystalline component (the composition is the same, but the black glasses contain tiny crystals formed because of a decrease in the cooling rate).

One additional component of the lunar regolith is nanophase iron, located in agglutinates and within amorphous rims on lunar minerals exposed to space weathering. Nanophase iron is metallic iron globules. These globules can be between a few nm up to several hundred $\mathrm{nm}$ in size (e.g.; James et al., 2002). Nanophase iron forms by the reduction of $\mathrm{Fe}$ in coordination with $\mathrm{O}$ in mineral structures and glasses. There are many proposed methods of nanophase iron formation. One involves the reduction of Fe simply due to the thermal energy of an impact (Sasaki et al., 2001). Another is the reduction of Fe during micrometeorite impact vaporization and vapor deposition (Hapke et al., 1975; Keller and McKay, 1993). The role, if any, of nanophase iron formation due to saturation of the lunar surface by highly reducing $\mathrm{H}$ in the solar wind, remains to be determined.

There are several minor or trace mineral phases present in the regolith that might become significant under some conditions, including sulfide minerals such as the most abundant lunar sulfide, troilite (FeS). Sulfur is frequently considered a deleterious constituent in manufacturing conditions. Troilite may be especially worrisome, as it is unstable in the presence of $\mathrm{H}_{2} \mathrm{O}$; it spontaneously decomposes into hydrated iron oxides and sulfuric acid. In similar manner, there are mineral phases containing phosphorus and halogen elements as primary constituents. There are also trace quantities of a number of other elements normally avoided on Earth, specifically Sb, As, Se and similar elements. The minerals and phases containing these elements are not known well for the Moon; such details will determine what their availability will be in any processing. 
There are other non-silicate minerals on the Moon as well, including oxides and spinels. Oxides, such as ilmenite $\left(\mathrm{FeTiO}_{3}\right)$, are a desirable source for oxygen production, as compared to the silicate minerals. Chromite $\left(\mathrm{FeCr}_{2} \mathrm{O}_{4}\right)$ is a spinel, and is a chromium ore when concentrations are high enough. It is also a desirable source for oxygen production, as compared to the silicate minerals. As with ilmenite, it occurs as a common trace mineral and is extremely abundant in very distinct regions on the lunar surface. Spinel (senso stricto, $\mathrm{MgAl}_{2} \mathrm{O}_{4}$ ) and spinel group minerals are common trace minerals in the lunar regolith. They may be of special interest when considering abrasion as they can be extremely hard, tough, and break with sharp edges.

Compared to Earth, the types and number of minerals that occur on the Moon are limited. For example, few of the hydrated minerals, minerals containing either $\mathrm{H}_{2} \mathrm{O}$ or $\mathrm{OH}$ in their structure, are known from the Moon. Such minerals are very common on Earth. Clay minerals and other minerals associated with terrestrial weathering are absent on the Moon. Minerals which form by precipitation from, or reaction in the presence of, water are absent. Thus sulfates, carbonates, and similar species do not exist on the Moon. Ultimately, the absence of such minerals will preclude using many of the resource recovery technologies on the Moon that are used on Earth. For example aluminum production requires a significant source of fluorine. On Earth, fluorine comes from the mineral fluorite, the deposits of which were formed by hot water. Similarly, commercial iron production requires the use of limestone, which is calcium carbonate.

\section{Lithology}

The word "lithology" literally means the study of rocks, and is a combination of the Greek words "lithos" for stone and "logia" for logic. The names of rocks place them in a conceptual framework - that is, the name of a rock can give one an idea of its chemical and physical origin, mineralogy, particle size, and closely associated rocks. There are different types of rocks on the lunar surface; lunar geologists most commonly use igneous and impact rock type descriptors for lunar rocks.

Igneous rocks can be divided into two types - extrusive (i.e.; lava, which has reached the surface) and intrusive (i.e.; magma, which has not reached the surface). Extrusive rocks cool relatively quickly compared to intrusive rocks, which are insulated by surrounding rocks. The size and composition of mineral crystals in the rock is a record of both depth of crystal formation and residence time of the magma as it ascends. Volcanic glass beads are one example of extrusive rocks on the Moon; they cooled exceedingly quickly. The mare basalts are also examples of extrusive rocks and are mixtures of crystals and glass with varying degrees of devitrification. Intrusive rocks are completely crystalline. Examples of intrusive rocks include the lunar magnesian suite. Table 2 provides a short list of the common rock types found on the Moon.

Table 2: Common igneous rock types on the lunar surface and their major minerals.

\begin{tabular}{|l|l|l|}
\hline Rock type & Major mineral(s) & Location \\
\hline Anorthosite & Plagioclase (anorthite), some olivine and/or pyroxene & Highlands \\
\hline
\end{tabular}




\begin{tabular}{|l|l|l|}
\hline Norite & Plagioclase, pyroxene & Highlands \\
\hline Troctolite & Plagioclase, olivine & Highlands \\
\hline Basalt & Pyroxene, olivine, some plagioclase and ilmenite & Mare \\
\hline
\end{tabular}

When rocks are shocked or heated by impact, new rocks can form and old rocks can be modified. These are known as impactites, a sub-class of metamorphic rocks. Stöffler and Grieve (2007) provided a classification scheme for impactites; figure 8 represents the types of impactites.

Metamorphic rocks, such as granulites, are also present on the Moon. The heat and pressure required to metamorphose the samples could be the result of heating from volcanic activity or other lunar interior heat sources (such as radioactivity or proximity to magma), or from the heat of impact.

\section{Locations of High Concentrations of Specific Minerals or Rocks}

It is becoming easier to identify locations with potential in situ resource utilization capability with increasing resolution of remote sensing techniques, and further study of "ground truth" samples collected by the Apollo and Luna missions.

\section{IImenite}

Ilmenite is in trace abundance in the highlands; it is found in much greater abundance in some of the high-Ti mare basalts (e.g.; McKay and Williams, 1979; Heiken and Vaniman, 1990). There are no good terrestrial analogs of these rocks, as ilmenite in the oxidized terrestrial environment has exsolutions of magnetite unlike the highly reduced pure ilmenite on the Moon. Ilmenite is important, because it is readily capable of being reduced in order to extract oxygen from the regolith (e.g.; Chambers et al., 1995). Other materials such as agglutinates, volcanic glass beads, olivine, and pyroxene can also be reduced to provide oxygen for a lunar habitat (e.g.; Brecher et al., 1975; Allen et al., 1996) but ilmenite is a preferred source for reasons of energy requirements (e.g.; Taylor and Carrier, 1993).

\section{Chromite}

Sunshine et al. (2010) determined that the spectral signature of two portions of Sinus Aestuum, measured by the Moon Mineralogy Mapper $\left(\mathrm{M}^{3}\right)$, match the mineral chromite. The chromite mineral signature is dominant in the spectra, although there may be minor amounts of other minerals such as plagioclase, pyroxene, and olivine associated with these deposits, thus physical sampling is required to completely characterize the deposits. There are very large ore grade deposits of chromite on Earth, and they are in rocks with compositions and origins analogous to those proposed by models of the lunar crust's origin.

Spinel 
Large concentrations of the mineral spinel have been reported in the inner ring of the Moscoviense Basin by Pieters et al. (2010). It was detected using the $\mathrm{M}^{3}$ instrument aboard Chandrayaan-1. There are no similar rocks on Earth.

\section{Anorthosite}

Anorthosite, senso stricto, was reported in lunar craters by Ohtake et al. (2010). The Multiband Imager on the Selenological and Engineering Explorer (SELENE) spacecraft detected areas of high abundance, nearly $100 \%$, of plagioclase. Sixty-nine areas in crater peaks, rims, rings, and ejecta were detected. These areas were chosen because of their high albedo and low (to no) regolith cover. A map of each detected anorthosite location is provided in the Ohtake et al. (2010) paper.

\section{Regolith}

Regolith can be used for many things, including sintering (e.g.; Taylor and Meek, 2005), radiation shielding (e.g.; Nealy et al., 1988; Miller et al., 2009), agriculture (e.g.; Drees and Wilding, 1989) and berm or habitat construction (e.g.; Faierson et al., 2010). It is a resource found all over the lunar surface.

\section{$\underline{\text { Topographic Features }}$}

The lunar surface is covered in interesting geologic features, including craters, volcanoes, rilles, and lava flows. These features in themselves provide a natural resource for lunar habitation and exploration.

Craters are the most abundant topographic feature on the Moon. They are essentially circular valleys with a surrounding rim mountain chain, some with ejecta rays. One could use the valley floors to provide a fairly flat surface for landing pads, road networks, and foundations for habitats. Crater rims can be used as a strategic position or communication base, provide the best views of the lunar landscape, and absorb the greatest number of solar rays.

Because of the low tilt $\left(1.5^{\circ}\right)$ of the Moon's spin axis relative to the ecliptic plane, craters that are in the polar regions provide areas of permanent shadow (valleys that receive no sunlight because it is blocked by the surrounding rim) and permanent sunlight. Regions of permanent darkness are exceedingly cold, as shown by the Lunar Reconnaissance Orbiter Diviner instrument results (Paige et al., 2010). The temperature of one permanently shadowed region was measured to be 29 Kelvin or $-244^{\circ} \mathrm{C}$. In stark contrast, nearby areas of constant sunlight can have an average temperature around $200 \mathrm{~K}$, and peak temperatures exceeding $300 \mathrm{~K}\left(27^{\circ} \mathrm{C}\right)$. Bussey et al. $(2005,2010)$ estimated the locations of near-permanent illumination at the lunar poles by examining lunar topography and the astronomical properties of the Moon.

Other topographic features of the Moon are related to volcanic activity. The relatively smooth lunar mare surfaces formed as a massive body of lava cooled. Contraction of 
the lava during cooling created some rilles, which are long, narrow valleys. Smaller and more sinuous rilles are thought to be collapsed lava tubes (tunnels in which lava flowed, which remained after the lava stopped flowing). The sinuous rilles may be the result of completely or only partially-collapsed lava tubes. It may be possible to place a lunar habitat within a lava tube at the end of a sinuous rille, which would greatly protect the habitat from space weathering.

One other benefit to living within a rille or other embedded habitat is the relatively constant temperature. The surface of the Moon at the equator can heat up to $390 \mathrm{~K}$ and cool to 104K during the Moon's day-night cycle (Glasstone, 1965). This daily change in temperature is only observed to a depth of approximately $1 \mathrm{~m}$. Below $1 \mathrm{~m}$, the temperature was measured during the Apollo missions to be relatively stable between 250K and 260K (Vaniman et al., 1991). The temperature below this depth depends on the heat flow from the lunar core (Weber et al., 2011) and the location and concentration of heat-producing radioactive elements. However, given the observed lack of temperature changes below $1 \mathrm{~m}$, man-made structures below this depth could anticipate constant thermal conditions over the lifetime of the structure.

\section{Summary}

This chapter describes most of the geologic resources available on the Moon, and complements chapters involving water on the Moon and such energy sources as helium-3. The regolith, geologic concentrations of minerals, and physical features of the Moon enable abundant in situ resource utilization and habitation opportunities. With the ever-increasing data acquired from and about the Moon, at higher resolutions, the pathway to self-sustaining lunar habitation and resource use will become clearer.

\section{$\underline{\text { References }}$}

Allen C. C., Morris R. V., and McKay D. S. (1996) Oxygen extraction from lunar soils and pyroclastic glass. Journal of Geophysical Research 101, 26085-26095.

Bowen N. L. (1913) Melting phenomena in plagioclase feldspars. American Journal of Science 35, 577-599.

Brecher A., Menke W. H., Adams J. B., and Gaffey M. J. (1975) The effects of heating and subsolidus reduction on lunar materials: An analysis by magnetic methods, optical, Mössbauer, and X-ray diffraction spectroscopy. Proceedings of the $6^{\text {th }}$ Lunar Science Conference, 3091-3109.

Bussey D. B. J., Fristad K. E., Schenk P. M., Robinson M. S., Spudis P. D. (2005) Constant illumination at the lunar north pole. Nature 434, 842.

Bussey D. B. J., McGovern J. A., Spudis P. D., Neish C. D., Noda H., Ishihara Y., and Sørensen S. -A. (2010) Illumination conditions of the south pole of the Moon derived using Kaguya topography. Icarus 208, 558-564. 
Canup R. M. and Asphaug E. (2001) Origin of the Moon in a giant impact near the end of the Earth's formation. Nature 412, 708-712.

Carrier W. D. III, Olhoeft G. R., and Mendell W. (1991) Physical properties of the lunar suface. In Lunar sourcebook: A user's guide to the Moon (G. H. Heiken, D. T., Vaniman, and B. M French, ed.s), 475-594.

Carrier W. D. III (2003) Particle size distribution of lunar soil. Journal of Geotechnical and Geoenvironmental Engineering 129, 956-959.

Chambers J. G., Taylor L. A., Patchen A., and McKay D. S. (1995) Quantitative mineralogical characterization of lunar high-Ti mare basalts and soils for oxygen production. Journal of Geophysical Research 100, 14391-14401.

Cintala M. J. (1992) Impact-induced thermal effects in the lunar and mercurian regoliths. Journal of Geophysical Research 97, 947-973.

Cole D. M., Taylor L. A., Liu Y., and Hopkins M. A. (2010) Grain-scale mechanical properties. In Engineering Science, Construction and Operations in Challenging Environments $\left(12^{\text {th }}\right)$, Earth and Space 2010, March 14-17, Honolulu HI, American Society of Civil Engineers.

Deer W. A., Howie R. A., and Zussman J. (1992) An Introduction to the rock-forming minerals, $2^{\text {nd }}$ edition, Longman Scientific and Technical, Harlow, 696pp.

Dence M. R. (1968) Shock zoning at Canadian craters: Petrography and structural implications. In Shock Metamorphism of Natural Materials (B. M. French and N. M. Short, eds.) Mono Book Corp., Baltimore. 169-184.

Drees L. R. and Wilding L. P. (1989) Pedology, pedogenesis, and the lunar surface. In Lunar Base Agriculture: Soils for Plant Growth (D. W. Ming and D. L. Henninger, ed.s), 69-83.

Elkins-Tanton L. T., Burgess S., and Yin Q. -Z. (2011) The lunar magma ocean: Reconciling the solidification process with lunar petrology and geochronology. Earth and Planetary Science Letters 304, 326-336.

Faierson E. J., Logan K. V., Stewart B. K., and Hunt M. P. (2010) Demonstration of concept for fabrication of lunar physical assets utilizing lunar regolith simulant and a geothermite reaction. Acta Astronautica 67, 38-45.

French B. M. (1998) Traces of Catastrophe: A handbook of shock-metamorphic effects in terrestrial meteorite impact structures. LPI Contribution No. 954, Lunar and Planetary Institute, Houston. 120pp. 
Glasstone S. (1965) Sourcebook on the Space Sciences. Van Nostrand, Princeton, 937pp.

Hapke B. (2001) Space weathering from Mercury to the asteroid belt. Journal of Geophysical Research 106, 10039-10073.

Hapke B., Cassidy W., and Wells E. (1975) Effects of vapor-phase deposition processes on the optical, chemical, and magnetic properties of the lunar regolith. The Moon 13, 339-353.

Hartmann W. K. and Davis D. R. (1975) Satellite-sized planetesimals and lunar origin. Icarus 24, 504-515.

Heiken G. H. and Vaniman D. T. (1990) Characterization of lunar ilmenite resources. Proceedings of the $20^{\text {th }}$ Lunar and Planetary Science Conference, 239-247.

Heiken G. H., McKay D. S., and Brown R. W. (1974) Lunar deposits of possible pyroclastic origin. Geochimica et Cosmochimica Acta 38, 1703-1718.

Heiken G., Vaniman D., and French B. M. (1991) Lunar Sourcebook: A User's Guide to the Moon. Cambridge University Press, New York, 736pp.

Hess P. C. (1989) Origins of igneous rocks. Harvard University Press, Cambridge MA, 336pp.

Hörz F., Grieve R., Heiken G., Spudis P., and Binder A. (1991) Lunar surface processes. In Lunar Sourcebook: A User's Guide to the Moon (G. H. Heiken, D. T. Vaniman, and B. M. French, eds.) Cambridge University Press, Cambridge. 61-120.

James C. Letsinger S., Basu A., Wentworth S. J., and McKay D. S. (2002) Size distribution of $\mathrm{Fe}^{0}$ globules in lunar agglutinitic glass. $33^{\text {rd }}$ Lunar and Planetary Science Conference. Abstract \#1827.

Karner J., Papike J. J., and Shearer C. K. (2004) Plagioclase from planetary basalts: Chemical signatures that reflect planetary volatile budgets, oxygen fugacity, and styles of igneous differentiation. American Mineralogist 89, 1101-1109.

Keller L. P. and McKay D. S. (1993) Discovery of vapor deposits in the lunar regolith. Science 261, 1305-1307.

Keller L. P. and McKay D. S. (1997) The nature and origin of rims on lunar soil grains. Geochimica et Cosmochimica Acta 61, 2331-2341.

Klein C. and Hurlbut C. S. Jr. (1993) Manual of Mineralogy. John Wiley \& Sons, Inc. New York, NY. 681pp. 
Lindsay J. F. (1975) A steady-state model for the lunar soil. Geological Society of America Bulletin 86, 1661-1670.

Lingenfelter R. E., Canfield E. H., and Hampel V. E. (1972) The lunar neutron flux revisited. Earth and Planetary Science Letters 16, 355-369.

Liu Y., Park J., Schnare D., Hill E., and Taylor L. A. (2008) Characterization of lunar dust for toxicological studies II: Texture and shape characteristics. Journal of Aerospace Engineering 21, 272-279.

Longhi J. (2003) A new view of lunar ferroan anorthosites: Postmagma ocean petrogenesis. Journal of Geophysical Research 108 (E8), 5083. Doi: 10.1029/2002JE001941.

Lucey P. G., Blewett D. T., Taylor G. J., and Hawke B. R. (2000) Imaging of lunar surface maturity. Journal of Geophysical Research 105, 20377-20386.

Lucey P., Korotev R. L., Gillis J. J., Taylor L. A., Lawrence D., Campbell B. A., Elphic R., Feldman W., Hood L. L., Hunten D., Mendillo M., Noble S., Papike J. J., Reedy R. C., Lawson S., Prettyman T., Gasnault O., and Maurice S. (2006) Understanding the lunar surface and space-Moon interactions. In Reviews in Mineralogy and Geochemistry, 60, New Views of the Moon (B. L. Jolliff, M. A. Wieczorek, C. K. Shearer, and C. R. Neal, eds.) Mineralogical Society of America, Chantilly VA. 83-219.

Mathew K. J. and Marti K. (2001) Lunar nitrogen: Indigenous signature and cosmic-ray production rate. Earth and Planetary Science Letters 184, 659-669.

McCubbin F. M., Steele A., Hauri E. H., Nekvasil H., Yamashita S., and Hemley R. J. (2010) Nominally hydrous magmatism on the Moon. Proceedings of the National Academy of Sciences 107, 11223-11228.

McKay D. S. and Williams R. J. (1979) A geologic assessment of potential lunar ores. In Space Resources and Space Settlements (J. Billingham, W. Gilbreath, and B. O'Leary ed.s), 243-255.

McKay D. S., Heiken G., Basu A., Blanford G., Simon S., Reedy R., French B. M., and Papike J. (1991) The lunar regolith. In Lunar Sourcebook: A User's Guide to the Moon (G. H. Heiken, D. T. Vaniman, and B. M. French, eds.) Cambridge University Press, Cambridge. 285-356.

McKay D. S., Fruland R. M, and Heiken G. H. (1974) Grain size and the evolution of lunar soils. Proceedings of the $5^{\text {th }}$ Lunar Science Conference, 887-906.

Miller J., Taylor L., Zeitlin C., Heilbronn L., Guetersloh S., DiGiuseppe M., Iwata Y., and Murakami T. (2009) Lunar soil as shielding against space radiation. Radiation Measurements 44, 163-167. 
Morimoto N. (1988) Nomenclature of pyroxenes. Mineralogical Magazine 52, 535-550.

Morris R. V. (1978) The surface exposure (maturity) of lunar soils: Some concepts and $\mathrm{I}_{\mathrm{s}} / \mathrm{FeO}$ compilation. Proceedings of the $9^{\text {th }}$ Lunar and Planetary Science Conference, 2287-2297.

Nealy J. E., Wilson J. W., and Townsend L. W. (1988) Solar-flare shielding with regolith at a lunar base site. NASA Technical Paper 2869, 18pp.

Ohtake M., Matsunaga T., Haruyama J., Yokota Y., Morota T., Honda C., Ogawa Y., Torii M., Miyamoto H., Arai T., Hirata N., Iwasaki A., Nakamura R., Hiroi T., Sugihara T., Takeda H., Otake H., Pieters C. M., Saiki K., Kitazo K., Abe M., Asada N., Demura H., Yamaguchi Y., Sasaki S., Kodama S., Terazono J., Shirao M., Yamaji A., Minami S., Akiyama H., and Josset J. -L. (2010) The global distribution of pure anorthosite on the Moon. Nature 461, 236-240.

Pahlevan K. and Stevenson D. J. (2007) Equilibration in the aftermath of the lunarforming giant impact. Earth and Planetary Science Letters 262, 438-449.

Paige D. A., Siegler M. A., Zhang J. A., Hayne P. O., Foote E. J., Bennett K. A., Vasavada A. R., Greenhagen B. T., Schofield J. T., McCleese D. J., Foote M. C., DeJong E., Bills B. G., Hartford W., Murray B. C., Allen C. C., Snook K., Soderblom L. A., Calcutt S., Taylor F. W., Bowles N. E., Banfield J. L., Elphic R., Ghent R., Glotch T. D., Wyatt M. B., and Lucey P. G. (2010) Diviner lunar radiometer observations of cold traps in the Moon's south polar region. Science 330, 479-483.

Papike J. J., Hodges F. N., Bence A. E., Cameron M., and Rhodes J. M. (1976) Mare basalts: Crystal chemistry, mineralogy and petrology. Reviews in Geophysics and Space Physics 14, 475-540.

Papike J. J., Simon S. B., and Laul J. C. (1982) The lunar regolith: Chemistry, mineralogy, and petrology. Reviews of Geophysics and Space Physics 20, 761-826.

Papike J. J., Ryder G., and Shearer C. K. (1998) Lunar samples. In Planetary Materials (J. J. Papike, ed.) Mineralogical Society of America, Washington DC. 234pp.

Papike J. J., Karner J. M., and Shearer C. K. (2005) Comparative planetary mineralogy: Valence state partitioning of $\mathrm{Cr}$, Fe, Ti, and $\mathrm{V}$ among crystallographic sites in olivine, pyroxene, and spinel from planetary basalts. American Mineralogist 90, 277-290.

Parmentier E. M., Zhong S., and Zuber M. T. (2002) Gravitational differentiation due to initial chemical stratification: Origin of lunar asymmetry by the creep of dense KREEP?. Earth and Planetary Science Letters 201, 473-480. 
Pieters C. M., Fischer E. M., Rode O., and Basu A. (1993) Optical effects of space weathering: The role of the finest fraction. Journal of Geophysical Research 98, 2081720824.

Pieters C. M., Boardman J., Buratti B., Clark R., Combe J. P., Green R., Goswami J. N., Head J. W. III, Hicks M., Isaacson P., Klima R., Kramer G., Kumar K., Lundeen S., Malaret E., McCord T. B., Mustard J., Nettles J., Petro N., Runyon C., Staid M., Sunshine J., Taylor L. A., Thaisen K., Tompkins S., and Varanasi P. (2010) Identification of a new spinel-rich lunar rock type by the Moon Mineralogy Mapper $\left(\mathrm{M}^{3}\right)$. $41^{\text {st }}$ Lunar and Planetary Science Conference, Abstract \#1854.

Sasaki S., Nakamura K., Hamabe Y., Kurahashi E., and Hiroi T. (2001) Production of iron nanoparticles by laser irradiation in a simulation of lunar-like space weathering. Nature 410, 555-557.

Sharp Z. D., Shearer C. K., McKeegan K. D., Barnes J. D., and Wang Y. Q. (2010) The chlorine isotope composition of the Moon and implications for an anhydrous mantle. Science. doi:10.1126/science.1192606.

Shkuratov Y. G. and Bondarenko N. V. (2001) Regolith layer thickness mapping of the Moon by radar and optical data. Icarus 149, 329-338.

Smith J. V., Anderson A. T., Newton R. C., Olsen E. J., Wyllie P. J., Crewe A. V., Isaacson M. S., and Johnson D. (1970) Petrologic history of the Moon inferred from petrography, mineralogy, and petrogenesis of Apollo 11 rocks. Proceedings of the Apollo 11 Lunar Science Conference, 897-925.

Stoeser D. B., Benzel W. M., Schrader C. M., Edmunson J. E., and Rickman D. L. (2011) Notes on lithology, mineralogy, and production for lunar simulants. NASA technical memorandum 2011-216454, 49pp.

Stöffler D. and Grieve R. A. F. (2007) Impactites. Recommendations by the IUGS Subcommission on the Systematics of Metamorphic Rocks. IUGS Subcommission on the Systematics of Metamorphic Rocks 15.

Sunshine J. M., Besse S., Petro N. E., Pieters C. M., Head J. W., Taylor L. A., Klima R. L., Isaacson P. J., Boardman J. W., Clark R. C., and the $\mathrm{M}^{3}$ Team (2010) Hidden in plain sight: Spinel-rich deposits on the nearside of the Moon as revealed by Moon Mineralogy Mapper $\left(\mathrm{M}^{3}\right)$. $41^{\text {st }}$ Lunar and Planetary Science Conference, Abstract \#1508.

Taylor L. A. and Carrier W. D. III (1993) Oxygen production on the Moon: An overview and evaluation. In Resources of Near-Earth Space (J. Lewis, M. S. Matthews, and M. L. Guerrieri, ed.s), 69-108. 
Taylor L. A. and Meek T. T. (2005) Microwave sintering of lunar soil: properties, theory, and practice. Journal of Aerospace Engineering 18, 188-196.

Taylor L. A., Pieters C. M., Keller L. P., Morris R. V., and McKay D. S. (2001) Lunar mare soils: Space weathering and the major effects of surface-correlated nanophase Fe. Journal of Geophysical Research 106, 27985-27999.

Taylor L. A., Pieters C., Patchen A., Taylor D. -H. S., Morris R. V., Keller L. P., and McKay D. S. (2010) Mineralogical and chemical characterization of lunar highlands soils: Insights into the space weathering of soils on airless bodies. Journal of Geophysical Research 115, E02002, doi: 10.1029/2009JE003427.

Vaniman D., Reedy R., Heiken G., Olhoeft G., and Mendell W. (1991) The lunar environment. In Lunar Sourcebook: A User's Guide to the Moon (G. H. Heiken, D. T. Vaniman, and B. M. French, eds.) Cambridge University Press, Cambridge. 27-60.

Weber R. C., Lin P. -Y., Garnero E. J., Williams Q., and Lognonné P. (2011) Seismic detection of the lunar core. Science 331, 309-312.

Wilhelms D. E. (1987) The geologic history of the Moon. United States Geological Survey Professional Paper 1348.

Wong N., Santarius J., Taylor L. A., Garrison D. H., James, J. T., McKay D. S., and Kuhlman K. R. (2010) Decay of reactivity in forsterite due to UV radiation. Earth and Space 2010, 29-35.

Wood J. A., Dickey J. S., Marvin U. B., and Powell B. N. (1970) Lunar anorthosites and a geophysical model of the Moon. Proceedings of the Apollo 11 Lunar Science Conference, 965-988.

Yoder H. S., Stewart D. B., and Smith J. R. (1957) Ternary feldspars. Carnegie Institution of Washington yearbook 56, 206-216.

\section{Figure captions:}

Figure 1: Regolith components and physical properties. (a) This large boulder is a part of the lunar regolith. Astronaut Harrison Schmitt for scale. NASA photograph AS17140-21496. (b) In situ regolith. NASA photograph AS11-40-5878. (c) A portion of Apollo sample 76335 (a magnesian suite troctolite). (d) Scanning electron microscope image of an agglutinate. Photo credit D. S. McKay, NASA Johnson Space Center. (e) Orange and black volcanic glass beads collected during the Apollo 17 mission. NASA photograph S73-15171. Beads range in size from 20 to 45 microns. (f) Lunar core sample 10004. NASA photograph S69-40945. Approximately half of the core section is unfilled due to a core design flaw and the dry, uncompressible property of the regolith. A large rock aided in keeping the remaining regolith in place. 
Figure 2: Scanning electron microscope image of a micrometeorite impact crater crosssection in an Apollo 16 sample $(62236,58)$. Black indicates edge of the thin section. Gray is plagioclase. Note the broken appearance of plagioclase in the majority of the sample, and the smooth glass of the impact crater site. White phases are pyroxenes.

Figure 3: Particle size distribution for lunar regolith samples $<10 \mathrm{~mm}$ in size (redrawn from Carrier, 2003). Solid line indicates calculated average size of lunar regolith particles. Dashed lines indicate one sigma variation of the average particle size. Percent passing indicates the relative amount of material passing through a sieve with a particular mesh size.

Figure 4: Some particle textures for Apollo 16 regolith. (a) Poikiloblastic, coarse granulite (center clast). Photo taken in plane polarized light. Thin section 60009, 6020. (b) Intersertal plagioclase sphere with a pyroxene grain to left showing exsolution lamellae (two pyroxene compositions at different crystallographic orientations). Picture taken in crossed nicols. Thin section 60009,6020 . (c) Spherulitic texture as a result of devitrification. Photo taken in plane polarized light. Thin section 68001, 6031. (d) Holohyaline volcanic glass bead. Photo taken in plane polarized light. (e) Subophitic clast, to the left of a hypocrystalline agglutinate, picture taken in plane polarized light. (f) Reflected light image of (e), showing the size of the subophitic clast and agglutinate.

Figure 5: The olivine composition-temperature phase diagram at 1 atmosphere, redrawn from Klein and Hurlbut (1993). The solidus (bottom, below this curve everything is solid) and liquidus (top, above this curve everything is melt) are shown. Between the solidus and liquidus curves is a mixture of crystals and melt. A discussion of phase diagrams, tying melt composition to the composition of early- and late-forming crystals, as well as the temperature of melting and temperature of crystallization, can be found in Hess (1989). Lunar olivine compositions have a great range, from approximately $30 \%$ $\mathrm{Mg}_{2} \mathrm{SiO}_{4}$ in Fe-rich mare basalts to approximately $95 \% \mathrm{Mg}_{2} \mathrm{SiO}_{4}$ in magnesian suite samples (e.g.; Papike et al., 1998; represented by the light gray area). However, some extremely Fe-rich olivines $\left(0-10 \% \mathrm{Mg}_{2} \mathrm{SiO}_{4}\right.$, represented by the dark gray area) have been found in extremely late stage crystallization mineral assemblages (Papike et al., 1998).

Figure 6: The plagioclase temperature-composition diagram (Deer et al., 1992), indicating solidus and liquidus temperatures for anhydrous conditions at 1 bar pressure (top; Bowen, 1913) and 5kbar $\mathrm{H}_{2} \mathrm{O}$ conditions (bottom; Yoder et al., 1975). Highlighted area indicates compositions of lunar plagioclase (Papike et al., 1976). There is currently a debate as to the quantity of water on the Moon or in its interior, from anhydrous to relatively $\mathrm{H}_{2} \mathrm{O}$-rich (c.f.; Sharp et al., 2010; and McCubbin et al., 2010; respectively). Pressures studied for anorthosite genesis range from $1 \mathrm{bar}$ to $47 \mathrm{kbar}$ (Longhi, 2003).

Figure 7: Pyroxene Ca-Mg-Fe quadrilateral showing mineral names (Morimoto, 1988) and approximate range of lunar pyroxenes according to Heiken et al. (1991). 
Figure 8: Impactite classification after Stöffler and Grieve (2007), as presented by Stoeser et al. (2011). *Typically monomict. ${ }^{* *}$ Generally polymict but can be monomict (e.g., in a single lithology target). $\quad * \star *$ Includes glassy, hypocrystalline, and holocrystalline varieties. 


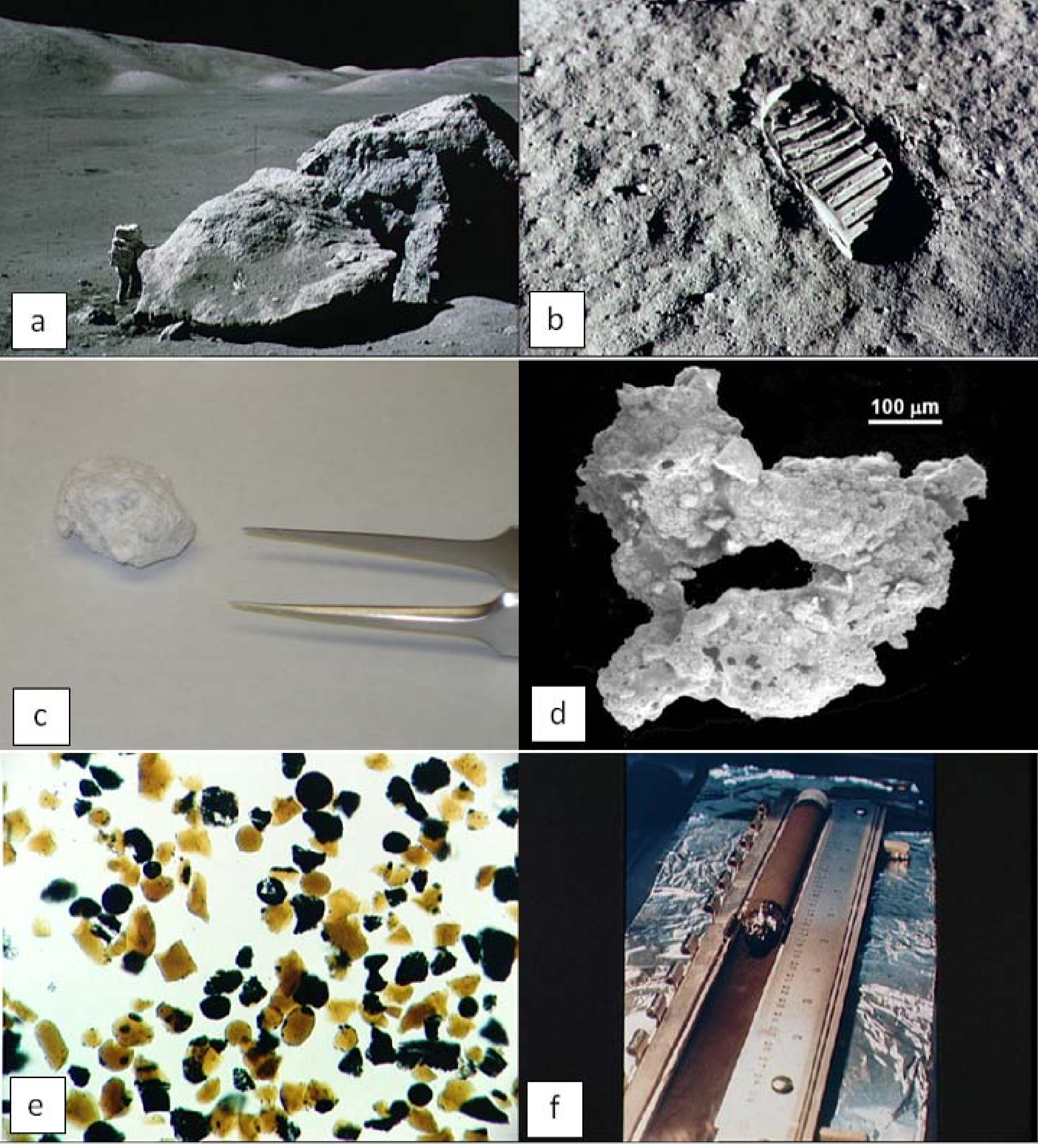




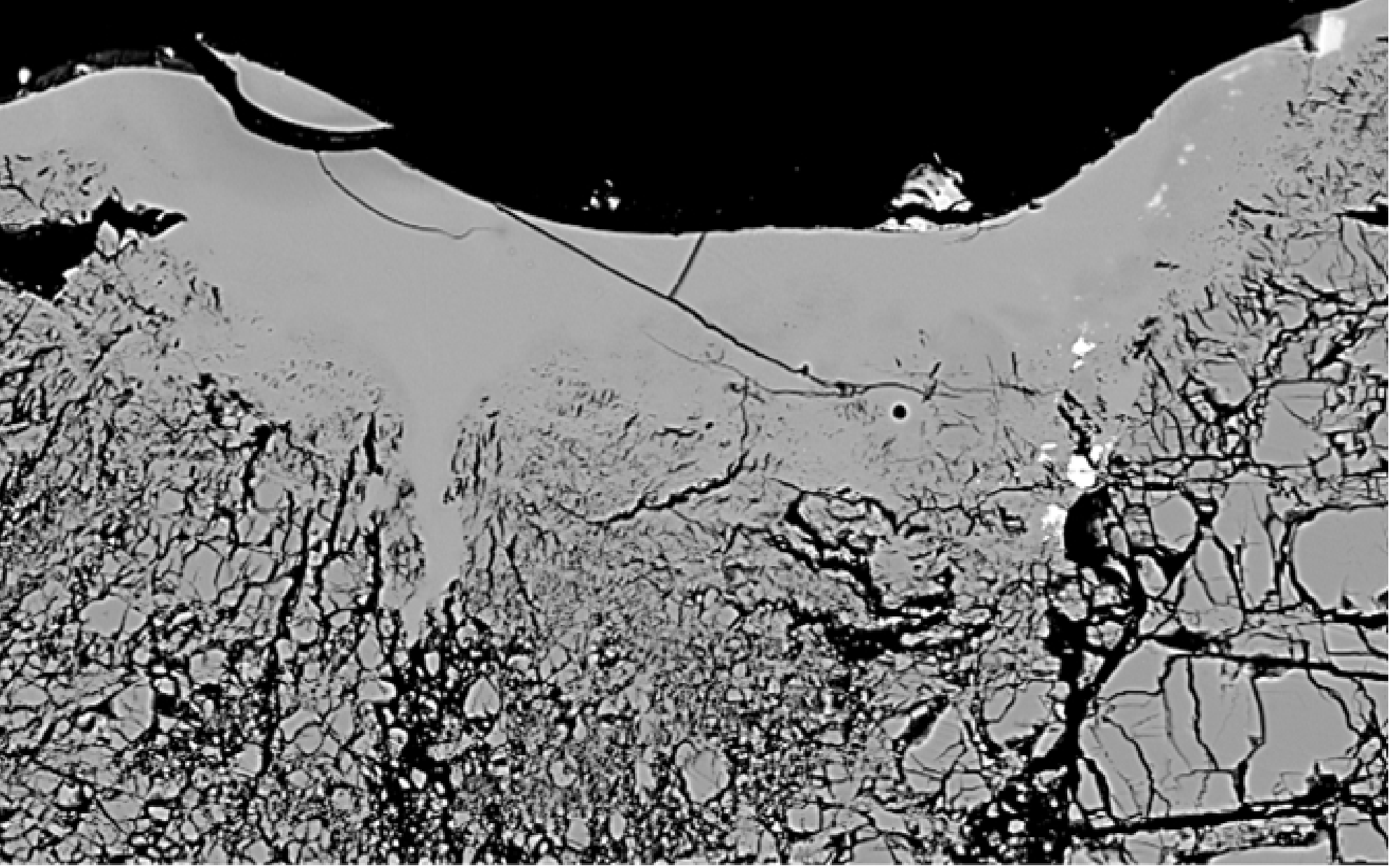




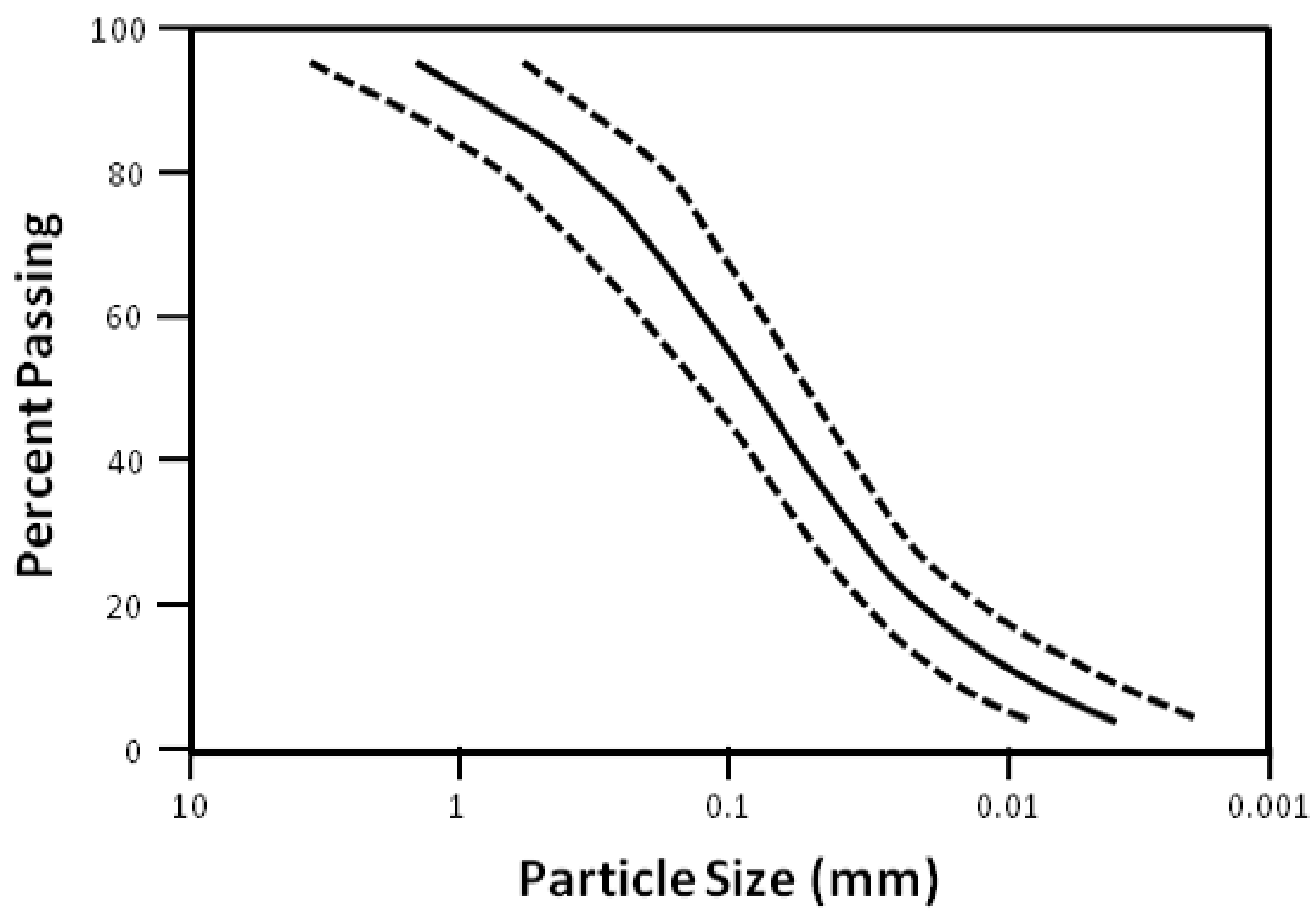




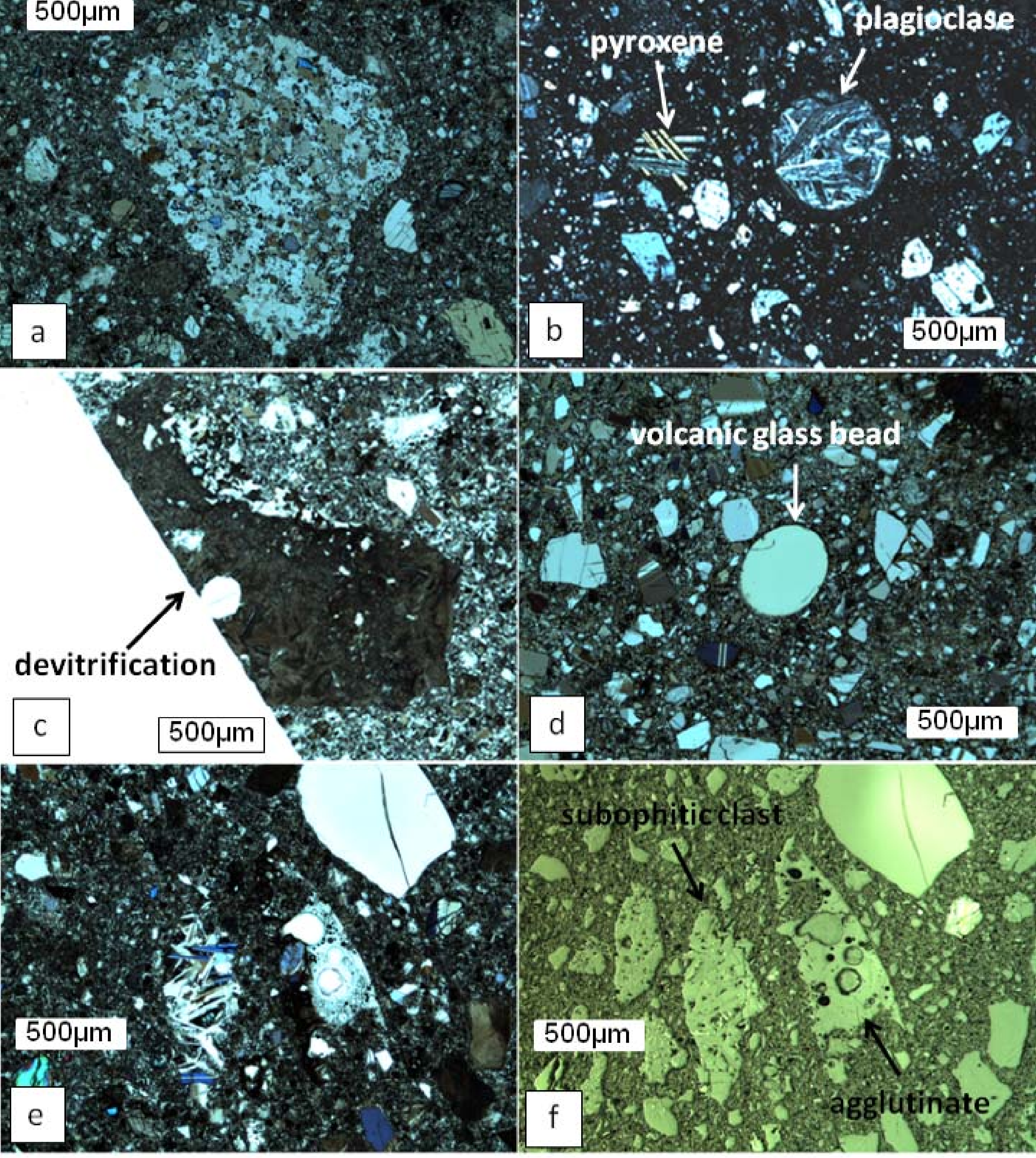




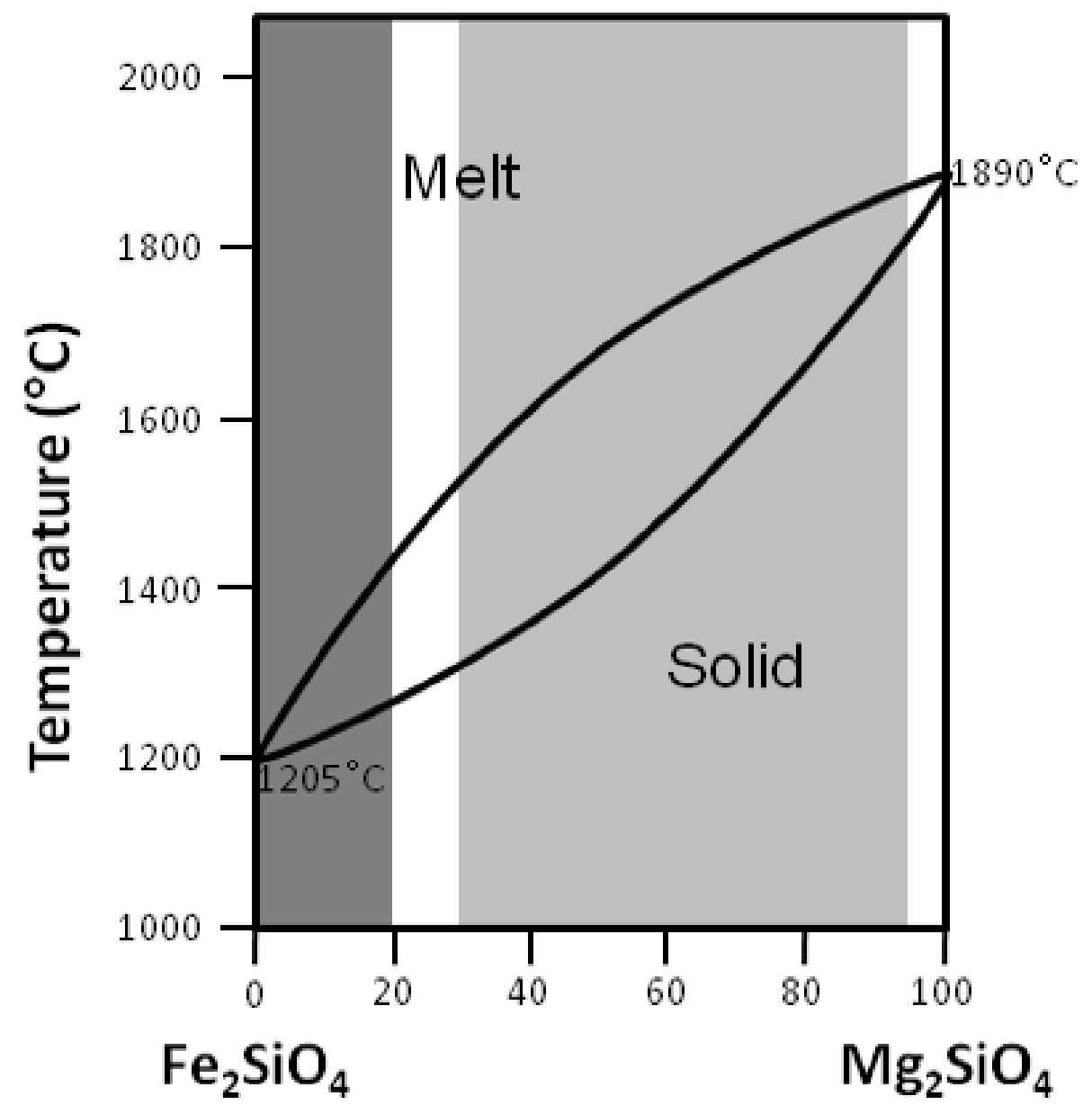




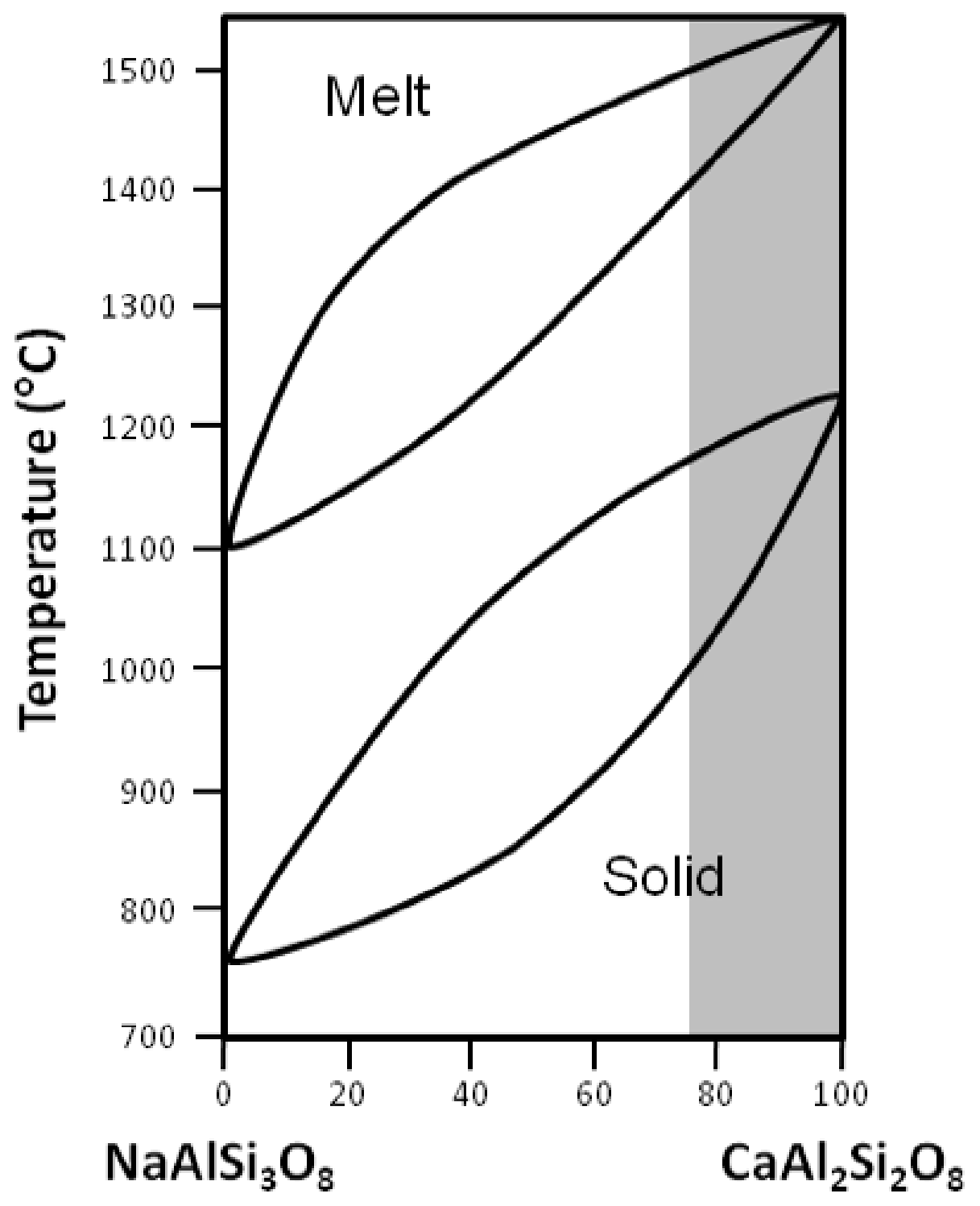




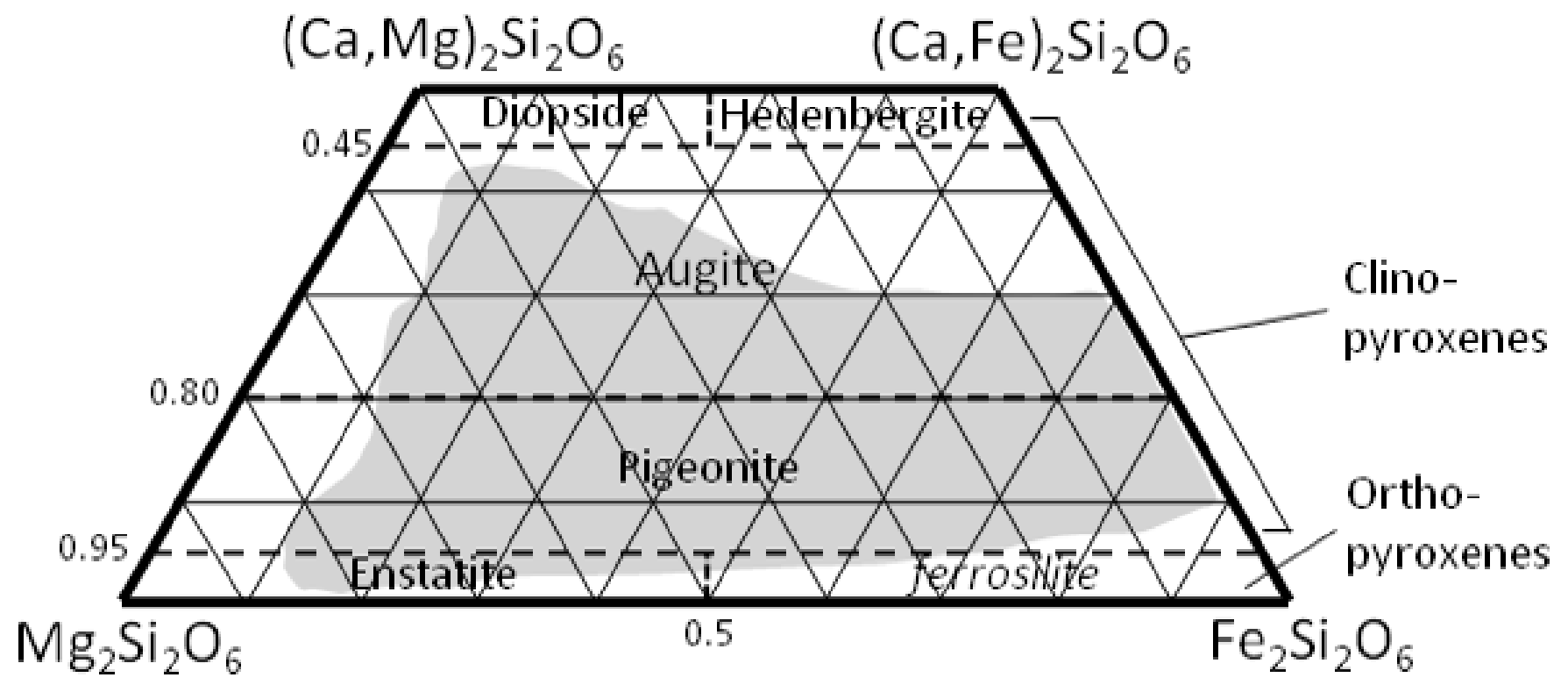



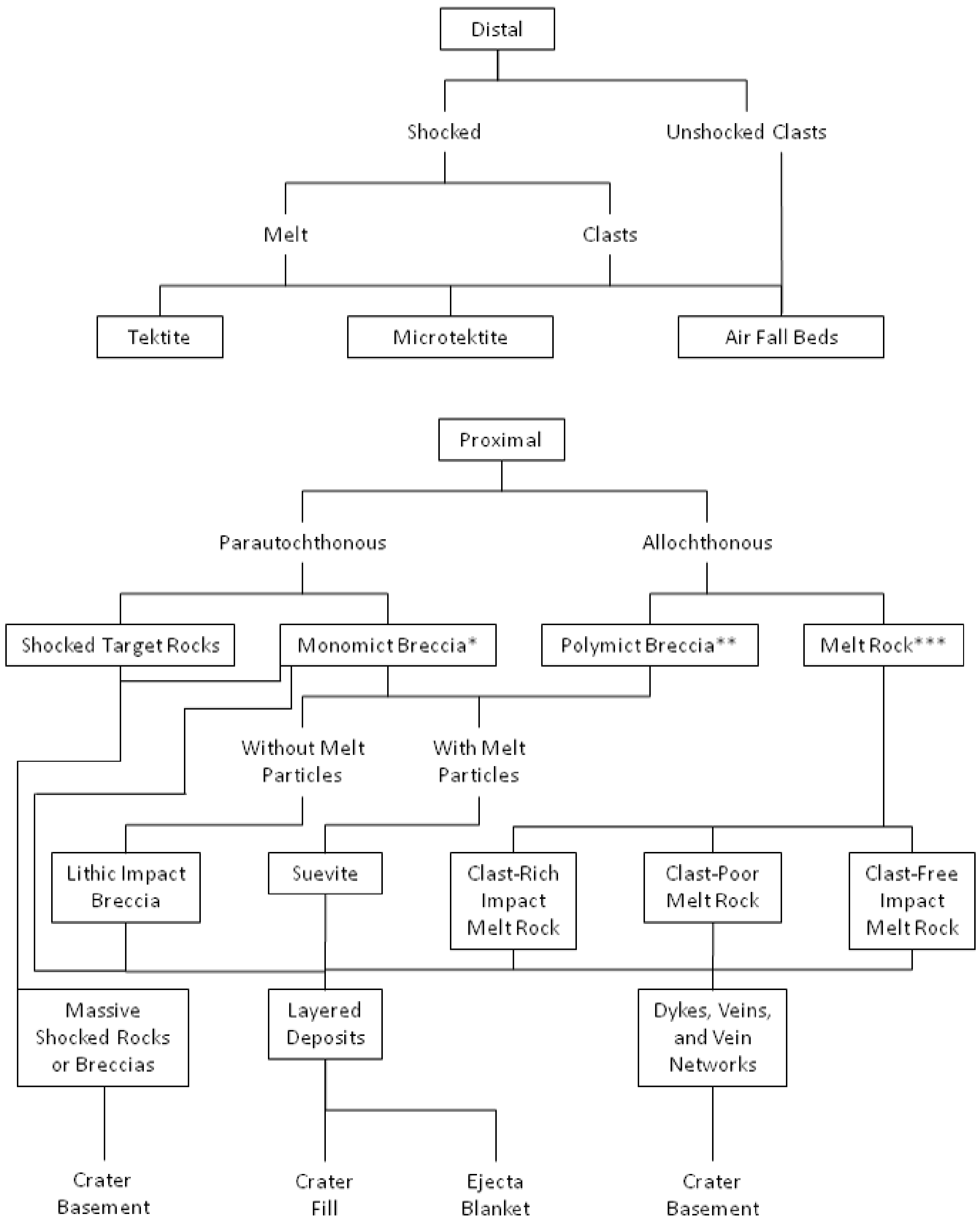